\title{
SISTEM MEDIA CENTER PERIKLANAN PAMERAN DI BANDUNG BERBASIS RASPBERRY PI MENGUNAKAN SERVIIO
}

\section{MEDIA CENTER SYSTEM FOR BANDUNG'S EXHIBITION ADVERTISING BASED RASPBERRY USING SERVIIO}

\author{
Denny Darlis ${ }^{1}$, Rohmat Tulloh ${ }^{2}$, Sheptian Kurnia Saleh ${ }^{3}$ \\ 1,2,3Program Studi D3 Teknik Telekomunikasi, Fakultas Ilmu Terapan, Universitas Telkom \\ 1'denny.darlis@ tass.telkomuniversity.ac.id, ${ }^{2}$ rohmatth@ telkomuniversity.ac.id, \\ ssaleh.tian@gmail.com
}

\begin{abstract}
Abstrak
Pameran adalah suatu kegiatan penyajian produk untuk dikomunikasikan sehingga dapat diapresiasi oleh masyarakat luas. Pameran bisa disebut sebagai kegiatan promosi yang dilakukan oleh suatu produsen. Biasanya pada saat pameran di sediakan booth yang berisi Televisi,layar monitor atau alat promosi lain. Namun booth yang biasa disediakan sempit sehingga harus pintar memilih alat promosi yang dibutuhkan agar booth tersebut terlihat menarik. Solusi agar booth tersebut terlihat minimalis adalah dengan dibuatnya sebuah server untuk mengatur segala yang ditampilkan di Televisi yang mempunyai fitur Digital Living Network Alliance Data yang akan diperlihatkan di simpan pada Raspberry Pi yang mempunyai aplikasi serviio dan bersertifikat Digital Media Server lalu sambungkan dalam satu jaringan WiFi setelah itu sindmkronsasi antara client dan server. Apabila sudah di sinkronisasi maka data tersebut bisa di akses oleh client. Hasil yang diperoleh yaitu dari pihak client bisa memperlihatkan data yang ada di server. Pada saat proses sinkronisasi membutuhkan waktu relatif lama dengan persentase keberhasilan $80 \%$ karena tergantung oleh banyaknya client.
\end{abstract}

Kata kunci : Digital media server, Serviio, WiFi, Raspberry Pi

\begin{abstract}
The exhibition is a presentation of product to be communicated so that it can be appreciated by the public. The exhibition can be called as the promotional activities undertaken by a producer. Usually at the exhibition booth is provided which contains a Television and other promotional tools. But the usual booth provided a narrow and should be smart to choose a promotional tool is needed for the booth look interesting. The solution that the booth is the minimalist look made a server to set everything shown on Television that has Digital Living Network Alliance features. The data will be displayed in the store on Raspberry Pi that has a certified Digital Media Server application Serviio and then plug in a WiFi network after it synchronization between client and server. When it is in sync then the data can be accessed by the client. The results obtained from the client is able to show the data on the server. At the time of the synchronization process takes a relatively long time to percentage $80 \%$ success because it depends on the number of clients.
\end{abstract}

Keywords: Digital Media Server, Serviio, WiFi, Raspberry Pi 


\section{PENDAHULUAN}

Pada zaman sekarang sudah banyak metode periklanan produk-produk kebutuhan manusia dari mulai kebutuhan primer, sekunder dan tersier. Salah satu metode periklanan yang banyak dilakukan saat ini adalah lewat pameran yang biasanya bertempat di daerah yang ramai dikunjungi orang. Biasanya di setiap pameran teknologi, furnitur maupun rumah di sediakan booth yang di dalamnya terdapat TV berfungsi untuk menampilkan sebuah video periklanan, dokumen video tersebut disimpan di flashdisk di putar memakai DVD. Namun dikarenakan di sebuah pameran terdapat banyak booth, otomatis pada setiap booth harus menyiapkan sebuah flashdisk atau DVD dan itu sangat kurang efektif dan efisien.

Pembuatan media center pada pameran dapat menjadi solusi yang tepat dari permasalahan tersebut, anggaran untuk menghias booth dan menyewa tempat sudah mahal apalagi ditambah harus membeli flashdisk dan DVD. Seiring berjalannya waktu penerapan teknologi pada pameran ini akan membawa dampak besar untuk pengisi pameran, akan tetapi dibutuhkan sebuah komputer sebagai media streaming server, terlebih lagi dengan konsumsi daya yang tinggi dan tempat yang tidak mendukung untuk memasang sistem yang besar.

Pada penelitian ini dibuat sebuah media center yang diaplikasikan pada pameran. Sistem ini menggunakan Raspberry Pi sebagai media center dan akan di bagikan melalui jaringan WiFi. Kelebihan dari sistem ini adalah Raspberry Pi dapat digunakan sebagai media streaming server dengan ukuran yang sangat kecil (sebesar kartu ATM) dan juga tidak memerlukan daya yang tinggi.

\section{SISTEM PENDUKUNG}

\subsection{Single Board Computer}

Single Board Computer adalah komputer dalam sebuah board. Artinya apapun yang bisa dilakukan oleh komputer bisa dilakukan oleh SBC. SBC saat ini memiliki memori yang besar (128 MB-2 GB, bahkan sebagian sudah lebih), memiliki external storage (SD Card/USB disk), dan memiliki prosessor dalam dengan kecepatan ratusan Mhz sampai GHz, sebagian bahkan sudah quad core [1].

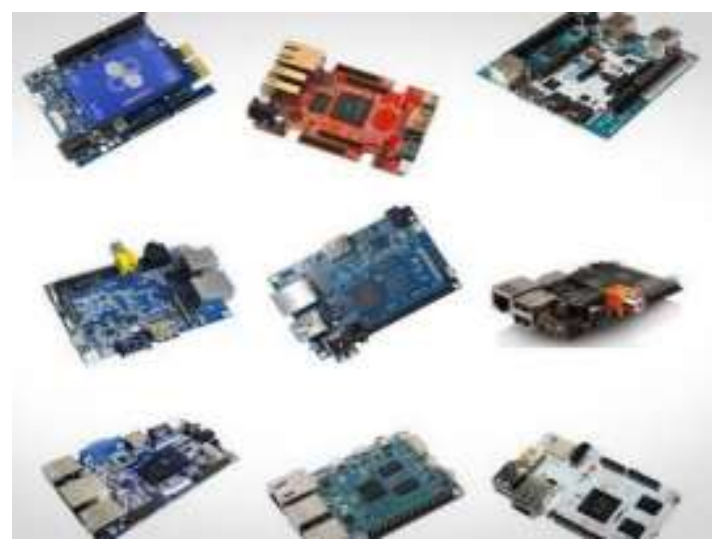

Gambar 1. Single Board Computer

\subsection{Wireless Fidelity (Wi-Fi)}

Wifi adalah singkatan dari wireless fidelity, teknologi WiFi adalah digunakan untuk menyediakan akses internet nirkabel di zona terbatas yang dikenal dengan istilah hotspot. WiFi adalah sebagai pengganti istilah Wireless LAN, walapun demikian setiap Wireless LAN tunggal (Local Area Network) tidak diharus disertifikasi oleh WiFi Alliance. WiFi adalah istilah lain dari Wireless LAN yang disertifikasi oleh WiFi platform standar jaringan IEEE 802.11[2]. 
Tabel 1. Spesifikasi Wifi[2]

\begin{tabular}{|c|c|c|c|}
\hline Spesifikasi & $\begin{array}{c}\text { Kecepatan } \\
(\mathrm{Mb} / \mathrm{s})\end{array}$ & $\begin{array}{c}\text { Frekuensi } \\
(\mathrm{GHz})\end{array}$ & Jenis \\
\hline $802.11 \mathrm{a}$ & 54 & 5 & $\mathrm{a}$ \\
\hline $802.11 \mathrm{~b}$ & 11 & 2.4 & $\mathrm{~b}$ \\
\hline $802.11 \mathrm{~g}$ & 54 & 2.4 & $\mathrm{~b}, \mathrm{~g}$ \\
\hline $802.11 \mathrm{n}$ & 100 & 2.4 & $\mathrm{~b}, \mathrm{~g}, \mathrm{n}$ \\
\hline
\end{tabular}

\subsection{Digital Living Network Alliance (DLNA)}

Salah satu fitur yang terdapat pada kebanyakan TV Digital saat ini adalah koneksi DLNA. DLNA singkatan dari Digital Living Network Alliance. Ini merupakan sebuah lembaga non profit yang dimotori oleh Sony dan didukung oleh banyak produsen elektronik terkemuka lainnya [3].

Keberadaan lembaga DLNA ini bertujuan menetapkan standar yang memungkinkan produk-produk elektronik dapat terhubung dan berbagi konten satu sama lain walaupun berbeda produsen. Lembaga ini melakukan sertifikasi terhadap produk-produk elektronik dari produsen yang menjadi anggota lembaga DLNA. Produk yang sudah mendapat setifikasi dari DLNA akan memiliki logo "DLNA CERTIFIED" [3].

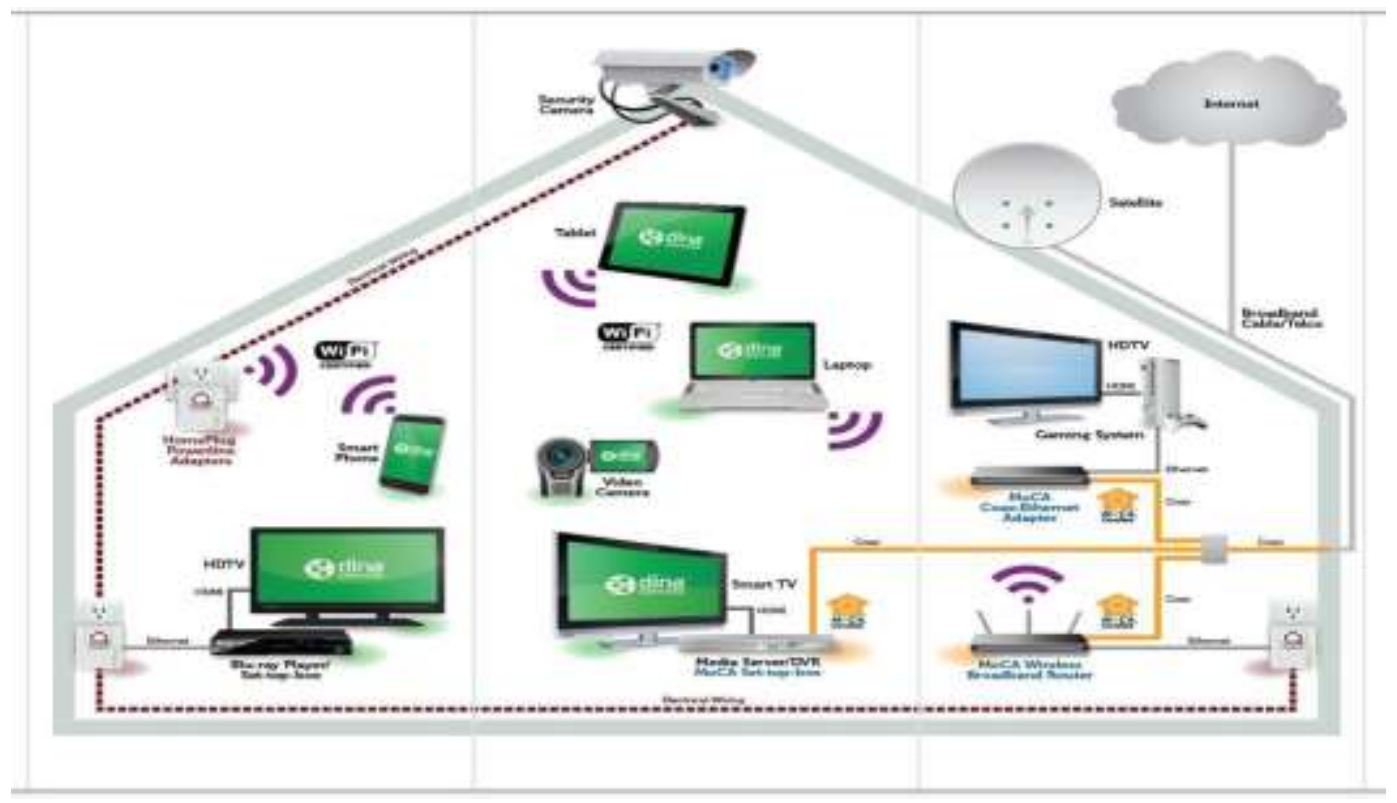

Gambar 2. Sistem DLNA[3]

Untuk memanfaatkan fitur DLNA ini ada dua syarat yang harus dipenuhi:

1. Tersedia jaringan dalam rumah, baik yang menggunakan kabel (LAN) atau tanpa kabel (wireless atau wifi). Jaringan ini sama seperti yang biasa kita gunakan untuk akses internet, seperti modem router.

2. Memiliki perangkat - perangkat elektronik yang ada fitur DLNA, seperti TV Digital, Smartphone, Tablet, Laptop dan sebagainya. 


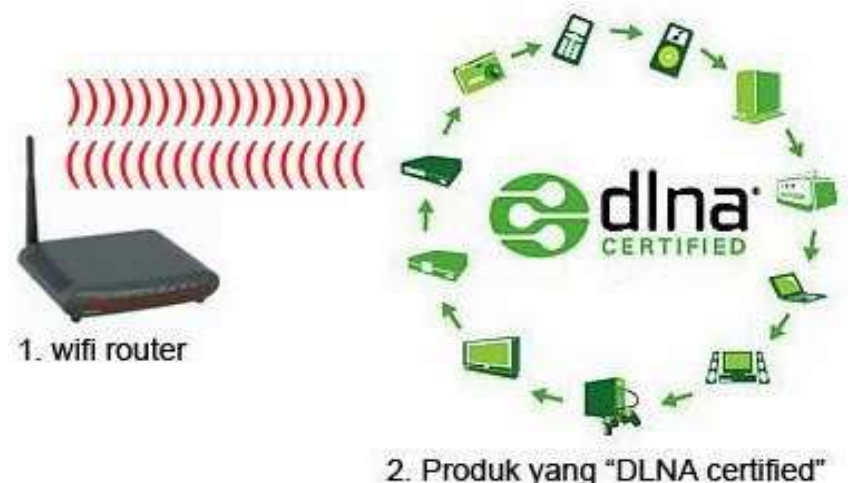

Gambar 3. Router dan DLNA certified

\subsection{Raspbian Wheezy}

Raspbian adalah operating system berbasis Deian GNU/linux dan dipotimalkan untuk perangkat keras Raspberry Pi. Raspbian dilengkapi dengan lebih dari 35.000 paket, pre-compiled software dibuat dalam format yang memudahkan proses instalasi.

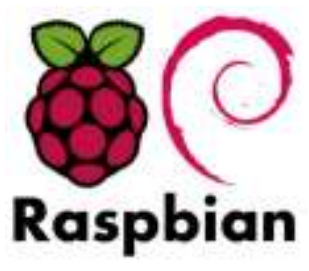

Gambar 4. Raspbian Wheezy

\subsection{Serviio}

Serviio dalah perangkat lunak grafis gratis yang ditulis dalam bahasa pemrograman Java dan dirancang untuk bertindak sebagai server media yang berguna, yang memungkinkan pengguna untuk melakukan streaming media mereka (file musik, video atau gambar) di beberapa perangkat dan platform.

\section{PERANCANGAN SISTEM}

Sistem yang dibuat pada penelitian ini adalah sebuah pusat media server dengan Raspberry Pi sebagai media server-nya. Sistem ini dibuat untuk dapat diaplikasikan pada sebuah pameran. Sistem ini dibuat memakai sistem kerja DLNA (Digital Living Network Alliance). Fitur yang ditampilkan hanya berupa video periklanan. Perangkat keras yang digunakan berupa Access Point yang dihubungkan dengan Raspberry Pi server, Wifi dongle dihubungkan dengan Raspberry Pi client untuk menerima sinyal WiFi dari server lalu ditampilkan pada sebuah monitor.

\subsection{Diagram Alir Perancangan Sistem}

Secara umum cara kerja alat yang dirancang pada penelitian ini ditunjukan oleh blok diagram sistem dibawah ini : 


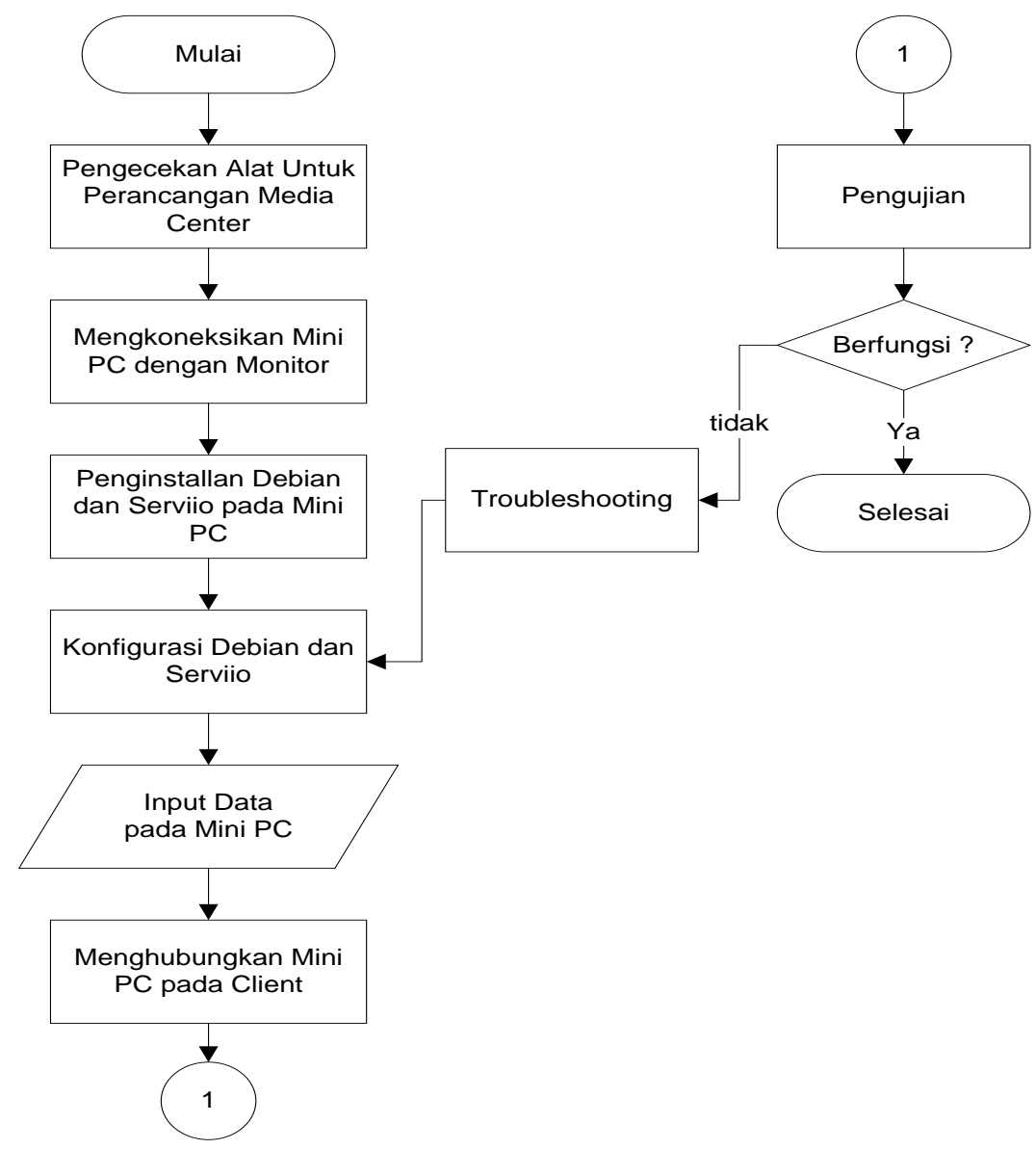

Gambar 5. Diagram alir perancangan sistem

\subsection{Perangkat Lunak}

Perangkat lunak yang digunakan dalam pembuatan aplikasi ini adalah sebagai berikut :

1. Raspbian Whezzy Raspbian digunakan sebagai operating system berbasis Deian GNU/linux dan dipotimalkan untuk perangkat keras Raspberry Pi. Raspbian dilengkapi dengan lebih dari 35.000 paket, pre-compiled software dibuat dalam format yang memudahkan proses instalasi.

2. OSMC (Open Source Media Center) adalah salah satu sitem operasi pada raspberry pi yang digunakan sebagai media player pada linux.

3. Serviio Serviio adalah perangkat lunak grafis gratis yang ditulis dalam bahasa pemrograman Java dan dirancang untuk bertindak sebagai server media yang berguna, yang memungkinkan pengguna untuk melakukan streaming media mereka (file musik, video atau gambar) di beberapa perangkat dan platform.

4. FFmpeg (Fast Forward Motion Picture Expert Group ) adalah program komputer yang dapat merekam, mengkonversi dan streaming digital dalam berbagai format. FFmpeg merupakan aplikasi command lineyang terdiri dari kumpulan pustaka perangkat lunak bebas / open source. Termasuk libavcodec, library untuk audio codec / video codec yang digunakan oleh beberapa proyek lain, dan libav format, library untuk audio / video mux kontainer dan demux kontainer.

5. Wireshark adalah tool yang ditujukan untuk melakukan analisa paket data jaringan. Wireshark melalukan monitoring paket secara real-time selanjutnya Wireshark melakukan 
penangkapan data dan menampilkannya selengkap mungkin. Aplikasi pada proyek akhir ini digunakan untuk mengukur bandwidth, latency, jitter dan packet loss.

\subsection{Implementasi Sistem Aplikasi Perangkat Keras}

Komponen elektronika utama pada penelitian ini menggunakan Raspberry Pi tipe B+ dan tipe B yang diproduksi oleh Element14. Keuntungan menggunakan board ini adalah terdapat banyak fitur yang dapat mendukung pembuatan sebuah media server dan dalam konfigurasi alat tidak terlalu sulit. Spesifikasi dari raspberry pi tipe B+ dan B dapat dilihat pada tabel 2 dan 3. Raspberry pi tipe $\mathrm{B}+$ yang mempunyai spesifikasi lebih tingi digunakan di bagian server, sedangkan untuk tipe B digunakan di bagian client.

Tabel 2. Spesifikasi Raspberry Pi model B+

\begin{tabular}{|c|c|c|}
\hline No. & Nama & Keterangan \\
\hline 1 & Memory & 512 MB RAM \\
\hline & Connections & $\begin{array}{l}\text { USB2.0 Ports with up to 1.2A } \\
\text { output, Video/Audio Out via 4- } \\
\text { pole 3.5mm connector, HDMI, } \\
\text { or Raw LCD (DSI), 10/100 } \\
\text { Ethernet (RJ45) }\end{array}$ \\
\hline 3 & SoC & Broadcom VideoCore IV GPU \\
\hline 4 & $\mathrm{CPU}$ & $\begin{array}{l}700 \mathrm{MHz} \text { ARM1176JZF-S } \\
\text { core CPU }\end{array}$ \\
\hline 5 & On board storage & Micro SD \\
\hline 6 & $\begin{array}{l}\text { Low-level } \\
\text { peripherals }\end{array}$ & $\begin{array}{l}27 \text { x GPIO, UART, I2C bus, } \\
\text { SPI bus with two }\end{array}$ \\
\hline 7 & Real-time clock & None \\
\hline 8 & Power rating & $700 \mathrm{~mA}, \max 5 \mathrm{~V}$ \\
\hline 9 & Power source & $5 \mathrm{~V}$ via Micro USB \\
\hline 10 & Size and weight & $85.60 \times 53.98 \mathrm{~mm} 45 \mathrm{~g}(1.6 \mathrm{oz})$ \\
\hline
\end{tabular}

Tabel 3. Spesifikasi Raspberry Pi model B

\begin{tabular}{|c|c|l|}
\hline No. & Nama & \multicolumn{1}{c|}{ Keterangan } \\
\hline 1 & Memory & 512 MB RAM \\
\hline 2 & Connections & $\begin{array}{l}\text { 2 USB Port, Ethernet, 3.5 mm Jack } \\
\text { Audio, HDMI. }\end{array}$ \\
\hline 3 & SoC & Broadcom BCM2835 \\
\hline 4 & CPU & $\begin{array}{l}700 \mathrm{MHz} \text { ARM1176JZF-S } \\
\text { core }\end{array}$ \\
\hline 5 & $\begin{array}{c}\text { On board } \\
\text { storage }\end{array}$ & Micro SD Card \\
\hline & $\begin{array}{c}\text { Low-level } \\
\text { peripherals }\end{array}$ & $\begin{array}{l}\text { 26 GPIO Pins, SPI bus, } \\
\text { I2C,I2S, UART }\end{array}$ \\
\hline 7 & Real-time clock & None \\
\hline 8 & Power rating & $700 \mathrm{~mA}$, max 5V \\
\hline 9 & Power source & $5 \mathrm{~V}$ via Micro USB \\
\hline 10 & Size and weight & $85 \mathrm{~mm} \times$ 56 mm x 17 mm - 40 g \\
\hline \multicolumn{2}{|c|}{} \\
\end{tabular}



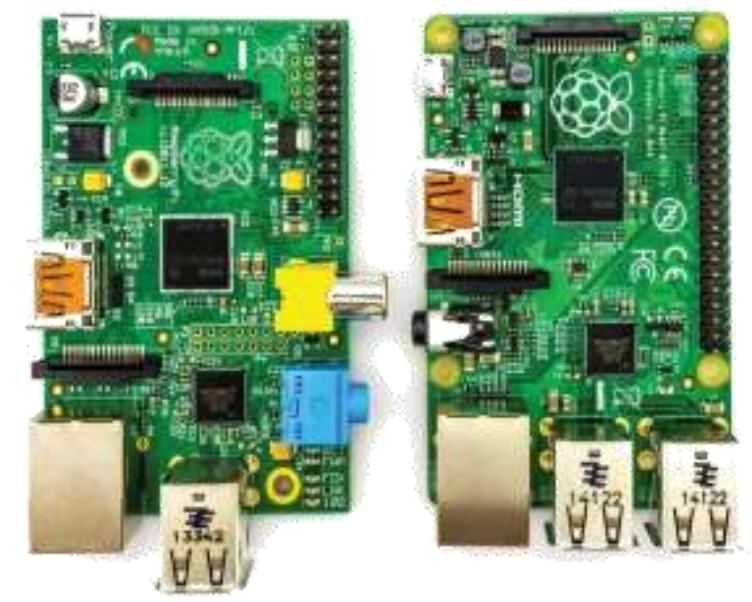

Gambar 6. Raspberry Pi model B dan B+

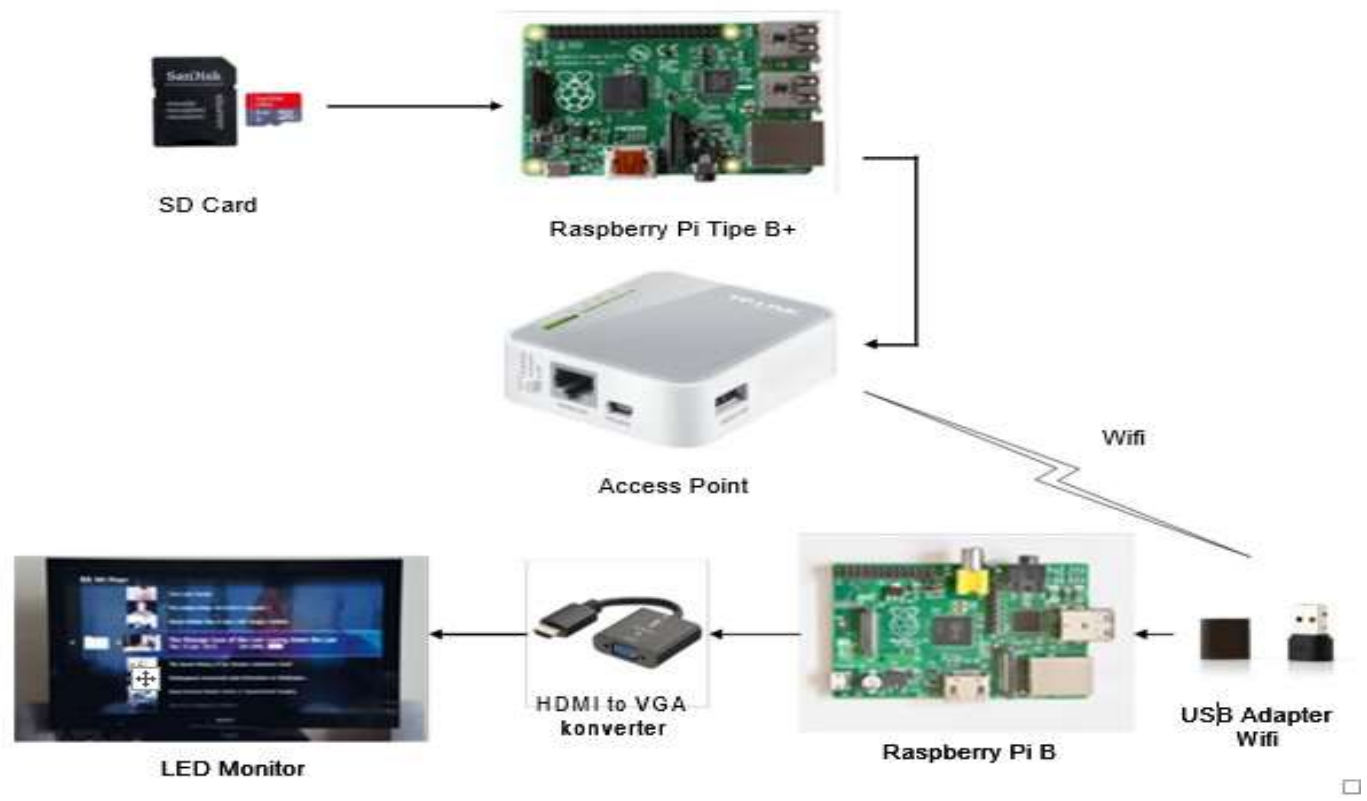

Gambar 7. Blok Diagram Perangkat Keras

Fungsi-fungsi dari setiap komponen pada blok diagram yang ditunjukan pada Gambar 7 adalah sebagai berikut :

1. SD Card digunakan untuk menyimpasn sistem operasi, aplikasi pendukung dan video.

2. Raspberry Pi B+ sebagai media sreaming server

3. Access Point digunakan untuk membagikan file video melalui jaringan Wifi.

4. USB adapter Wifi digunakan untuk menerima sinya Wifi dari server.

5. Raspberry Pi B digunakan sebagai client

6. HDMI to VGA konverter digunakan untuk menampilkan antarmuka sistem di Raspberry Pi B pada monitor.

\subsection{Skenario Pengujian}

Pengujian pertama adalah pengujian kinerja server dilakukan dengan cara memutar video dengan client raspberry pi lalu di bandingkan kinerja CPU dan RAM pada saat setelah diputar video dan saat sebelum diputarnya video. 
Pengujian kedua adalah pengujian Qos pada aplikasi. Dilakukan dengan menggunakan raspberry pi server dan client ditampilkan di LED monitor. Dimana pengukuran dimulai pada saat client terhubung dengan serviio melalui jaringan WiFi, melalui akses poin dengan kabel LAN yang terhubung dengan raspberry pi server lalu melakukan pembagian file media yang terdapat di rapberry pi server. Pengujian ini dilakukan dengan cara memutar video. Untuk memperoleh nilai parameter dalam pengujian, dilakukan proses pengambilan data trafik paket pada sisi raspberry pi server dengan menjalankan Wireshark pada saat raspberry pi client memutar video. Parameter pada pengujian kali ini adalah delay, packet loss dan troughput. Berikut ini adalah model skenario pengujian yang dilakukan.

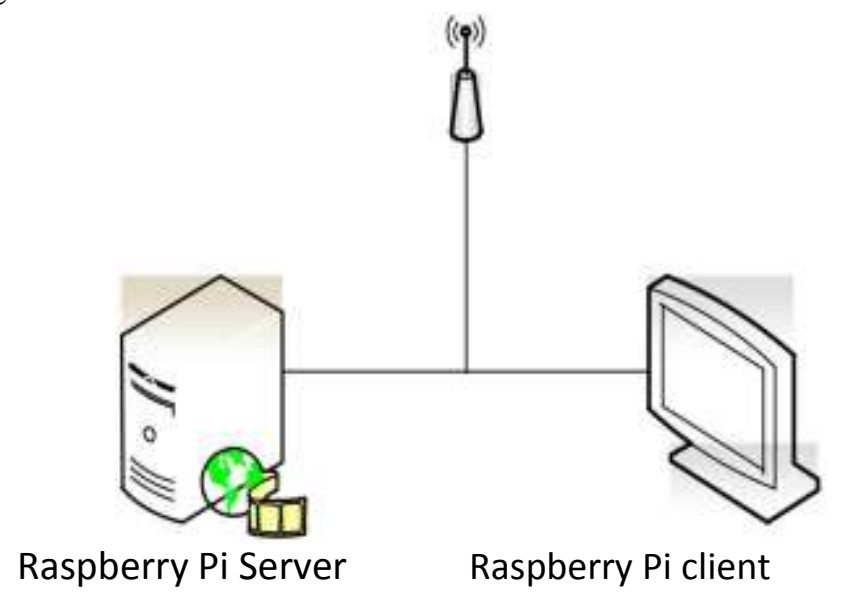

Gambar 8. Model skenario pengujian

\section{HASIL DAN PEMBAHASAN}

\subsection{Analisis Kinerja Server}

Dari pengukuran didapatkan bahwa raspberry pi server berjalan dengan baik, terbukti dengan di putarnya video pada 4 alat yang berbeda dan lancar tanpa ada delay. Rata-rata bila ada penambahan alat yang tersambung dengan server mengurangi kinerja RAM (Random Access Memory) sebesar $1 \mathrm{Mb}$. Pada saat pemutaran video pada 4 alat sekaligus memakan kinerja CPU sebanyak $100 \%$ yang membuat kinerja server menjadi sedikit lambat tetapi tidak menggaggu pada sisi client. Berikut grafik hasil pengujiannya:

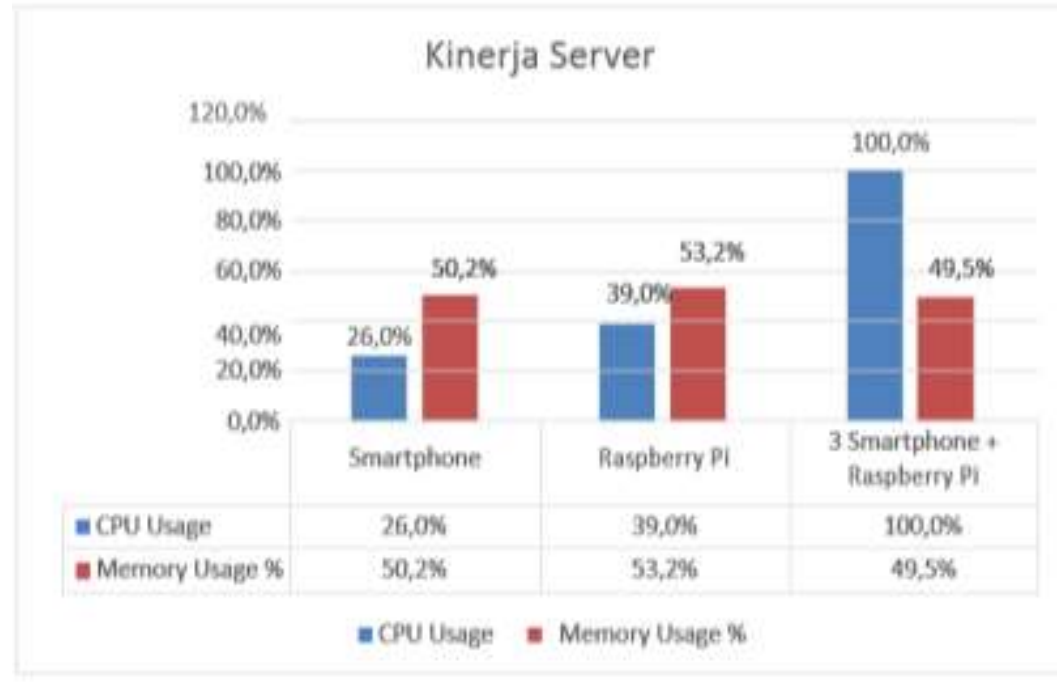

Gambar 9. Grafik kinerja server 
Tabel 4. Hasil tes kinerja server

\begin{tabular}{|l|l|l|l|l|}
\hline \multicolumn{1}{|c|}{ Client } & \multicolumn{1}{|c|}{ CPU Usage (\%) } & $\begin{array}{c}\text { Memory } \\
\text { Usage }(\mathrm{Mb})\end{array}$ & $\begin{array}{c}\text { Max Memory } \\
(\mathrm{Mb})\end{array}$ & $\begin{array}{c}\text { Memory } \\
\text { Usage (\%) }\end{array}$ \\
\hline Smartphone & $26,0 \%$ & 216 & 434 & $50,2 \%$ \\
\hline Raspberry Pi & $39,0 \%$ & 203 & 434 & $53,2 \%$ \\
\hline $\begin{array}{l}\text { 3 Smartphone + } \\
\text { Raspberry Pi }\end{array}$ & $100,0 \%$ & 219 & 434 & $49,5 \%$ \\
\hline
\end{tabular}

\subsection{Analisis Quality of Service (QoS)}

Pengujian Quality of Service ini dilakukan untuk mengetahui seberapa baik kualitas video yang di putar di client, pengujian ini dilakukan dengan menggunakan software Wireshark dan dilakukan selama 60 detik. Pengukuran dilakukan pada saat malam hari dalam keadaan server disimpan di dalam ruangan dan client di luar ruangan dengan dihalangi sebuah tembok.

Pengukuran ini dilakukan dengan smartphone sebagai client-nya, diukur dengan jarak kelipatan 4 meter dalam pemutaran video selama 60 detik hingga client tidak tersambung dengan wifi dan tidak bisa memutar video. Pada saat pengukuran jarak 16 meter client tidak mendapat sinyal wifi dan tidak bisa memutar video.

\subsubsection{Analisis Delay}

Dalam perhitungan delay berdasarkan hasil pengambilan data menggunakan wireshark dapat digunakan rumus persamaan berikut :

Delay $\mathrm{Tx}=($ Time between first and last packet $) /($ Jumlah Paket $)$

Untuk delay panggilan suara pada 15 detik pertama :

Delay $\quad=(40,078 / 18.999) \mathrm{s}$

$$
=2,019 \mathrm{~ms}
$$

Berdasarkan perhitungan delay secara matematis pada saat panggilan suara selama 60 detik, maka hasil perhitungan delay selama 120, 180, dan 240 jika dihitung dengan cara yang sama akan diperoleh hasil seperti pada Tabel 5 dibawah ini.

Tabel 5. Hasil Perhitungan Delay

\begin{tabular}{|l|l|l|l|l|}
\hline $\begin{array}{c}\text { Distance } \\
(\mathrm{m})\end{array}$ & $\begin{array}{c}\text { Sent } \\
\text { packets }\end{array}$ & $\begin{array}{c}\text { Time } \\
\text { beetween first } \\
\text { and last } \\
\text { packet }(\mathrm{s})\end{array}$ & $\begin{array}{c}\text { Troughpu } \\
\mathrm{t}(\mathrm{kpbs})\end{array}$ & $\begin{array}{c}\text { Delay } \\
(\mathrm{ms})\end{array}$ \\
\hline 0 & 18.999 & 40,078 & 387,122 & 2,019 \\
\hline 4 & 22.249 & 49,219 & 452,038 & 2,212 \\
\hline 8 & 17.654 & 49,876 & 353,96 & 2,825 \\
\hline 12 & 17.868 & 48,956 & 364,983 & 2,739 \\
\hline
\end{tabular}

\subsubsection{Analisis Packet Loss}

Dalam menghitung packet loss berdasarkan hasil pengujian diatas dapat menggunakan persamaan dibawah ini. Untuk packet loss pada saat pemutaran video streaming selama 60 detik, maka: 
Packet Loss $=[($ Paket Terkirim - Paket Diterima $) /($ PaketTerkirim $)] \times 100 \%$

$$
\begin{aligned}
& =[(18.999-18.999) / 18.999] \times 100 \% \\
& =0 \%
\end{aligned}
$$

Berdasarkan perhitungan packet loss pada saat streaming video selama 15 detik diatas, maka dengan rumus yang sama akan diperoleh hasil pada Tabel 6 dibawah ini:

Tabel 6. Hasil Perhitungan Packet Loss

\begin{tabular}{|c|l|c|c|}
\hline $\begin{array}{c}\text { Distance } \\
(\mathrm{m})\end{array}$ & $\begin{array}{c}\text { Sent } \\
\text { packets }\end{array}$ & $\begin{array}{c}\text { Time beetween first } \\
\text { and last packet (s) }\end{array}$ & $\begin{array}{c}\text { Packet } \\
\text { Loss (\%) }\end{array}$ \\
\hline 0 & 18.999 & 18.999 & 0 \\
\hline 4 & 22.249 & 22.249 & 0 \\
\hline 8 & 17.654 & 17.654 & 0 \\
\hline 12 & 17.868 & 17.868 & 0 \\
\hline
\end{tabular}

\subsubsection{Analisis Nilai MOS (Mean Opinion Score)}

Parameter-parameter yang digunakan adalah faktor-faktor yang mempengaruhi penurunan kualitas video dalam video streaming diantaranya adalah delay dan packet loss.

Comparison of MOS and R-factor Scores

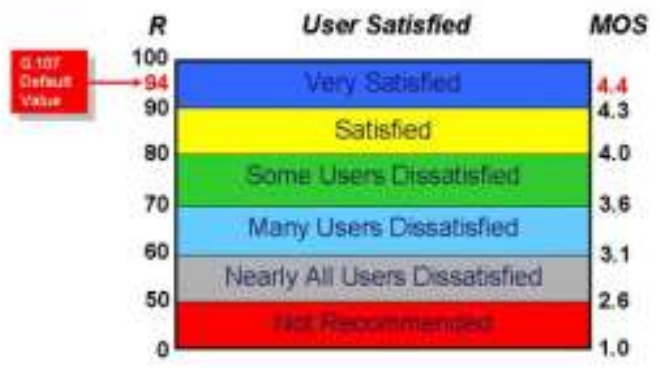

Gambar 10. Standar nilai MOS

Nilai akhir estimasi E-Model ini disebut dengan $\mathrm{R}$ faktor, didefiniskan sebagai berikut.

$$
\mathrm{R}=94.2-\text { Id }- \text { If }
$$

Atau secara umum persamaan nilai estimasi R Faktor menjadi :

$$
\mathrm{R}=94.2-[0.024 \mathrm{~d}+0.11(\mathrm{~d}-177.3) \mathrm{H}(\mathrm{d}-177.3)]-[7+30 \ln (1+15 \mathrm{e})]
$$

Dengan menggunakan rumus diatas, perhitungan MOS untuk video streaming adalah:

$$
\begin{aligned}
\mathrm{R}= & 94.2-[0.024 \times 18.40+0.11(18.40-177.3) \mathrm{H}(18.40-177.3)]- \\
& {[7+30 \ln (1+15 * 0.00061)] } \\
\mathrm{R}= & 87.258
\end{aligned}
$$

Nilai R-factor diatas dapat diubah kedalam bentuk MOS dengan rumus berikut :

$$
\begin{aligned}
\operatorname{MOS} & =1+0.035^{*} \mathrm{R}+\mathrm{R}(\mathrm{R}-60)(100-\mathrm{R}) * 7 * 10^{\wedge}(-6) \\
& =1+0.035 * 86.49+86.49(86.49-60)(100-86.49) * 7 * 10^{\wedge}(-6) \\
& =4.19
\end{aligned}
$$


Dari hasil perhitungan diatas maka didapatkan nilai MOS sebesar 4.19 atau setara dengan tingkat kepuasan Baik.

\section{KESIMPULAN}

Kesimpulan yang dapat diambil dari hasil pengujian yang telah dilakukan adalah :

1. Implementasi Media Streaming server pada Raspberry Pi berhasil dilakukan.

2. Video Streaming dapat berjalan dengan lancar yang dicoba di Raspberry Pi client dan smartphone dengan menggunakan aplikasi BubbleUPnP.

3. Jumlah total client sebanyak 4 dengan jumlah perangkat 1 Raspberry Pi client dan 3 smartphone melakukan pemutaran video secara bersamaan sehingga pada saat mulai kinerja CPU mencapai $100 \%$ setelah beberapa saat kembali stabil.

4. Untuk rata-rata pengukuran Qos Troughput yang didapat selama 60 detik pengujian adalah 389,52 Kbps, delay yang didapat $2.45 \mathrm{~ms}$, Packet loss yang didapat $0 \%$, Mos 4,19 dan setara dengan tingkat kepuasan Baik.

\section{DAFTAR PUSTAKA}

[1] Single-board-computer-dan-single-board-microcontroller [online] tersedia di http://cintaprogramming.com/2014/03/03 [diakses pada tanggal 04 Desember 2015 00:12]

[2] Cara Kerja wifi [online] tersedia di http://jaringankomputer.org/wifi-adalah-wireless-lancarakerja-sejarah-wifi [diakses tanggal 04 Desember 2015 00.45]

[3] www.dlna .org [diakses tanggal 04 Desember 2015 04.16]

[4] Secure Digital Card $\quad$ [online] $\quad$ tersedia di http://searchstorage.techtarget.com/definition/Secure-Digital-card [diakses tanggal 04 November 2014 08:43]

[5] Permadi, D.A. 2014. Impelementasi sistem papan ilkan digital menggunakan raspberry pi berbasis jaringan WLAN. Tugas Akhir Universitas Telkom. Bandung.

[6] Laode, Muhammad. 2015. Digital Information Center In Train Web Based Using Raspberry $\mathrm{Pi}$, Tugas Akhir Universitas Telkom. Bandung.

[7] Linux [online] tersedia di www.searchenterpriselinux.techtarget.com/definition/Linux [diakses tanggal 04 November 2014 08:43]

[8] Serviio [online] tersedia di www.serviio.org/ [diakses tanggal 04 November 2014 09:12]

[9] Computer Dictionary [online] tersedia di www.techterms.com/definition/ [diakses tanggal 03 November 2014 21:45] 